\title{
Seed dispersal potential of jackals and foxes in semi-arid habitats of South Africa
}

\author{
Jan F. Kamler, ${ }^{\mathrm{a}, *}$, Unn Klare ${ }^{\mathrm{b}}$, David W. Macdonald ${ }^{\mathrm{a}}$ \\ ${ }^{a}$ Wildife Conservation Research Unit, The Recanati-Kaplan Centre, Department of Zoology, \\ Oxford University, Tubney House, Abingdon Road, Tubney, Abingdon, OX13 5QL, United
}

Kingdom

${ }^{\mathrm{b}}$ University of Rostock, Weberstr. 11, 18069 Rostock, Germany

\begin{abstract}
ABTRACT
We determined the consumption of fruits and estimated potential seed dispersal of a canid community in semi-arid ecosystems of South Africa by comparing diets, defecation sites, densities and potential seed shadows of cape foxes (Vulpes chama), bat-eared foxes (Otocyon megalotis) and black-backed jackals (Canis mesomelas) on Benfontein and Rooipoort nature reserves. On Benfontein, all canid species consumed the fruit of Diospyros lycioides throughout the year. Jackals, but neither fox species, consumed relatively large amounts of Prosopis spp. (mesquite), an alien invasive. On Rooipoort, jackals had relatively high consumption of Ziziphus mucronata, followed by Grewia flava and D. lycioides. Bat-eared foxes had high consumption of fruit per area, although their seed dispersal potential was low due to their small potential seed shadow and poor germination sites. Cape foxes had the largest potential seed shadow, but their seed dispersal potential was low because of low fruit consumption, low density, and poor germination sites. Jackals had the highest seed dispersal potential because they consumed the most fruit species, had moderate densities, a relatively large potential seed shadow, and mostly

\footnotetext{
* Corresponding author. Tel: +44 1865611100

E-mail address: jan.f.kamler@gmail.com (J.F. Kamler)
} 
good germination sites. We conclude that seed dispersal potential of South African canids, especially jackals, is more significant than previously known.

Keywords: Bat-eared fox, black-backed jackal, cape fox, density, home range, seed shadow

\section{Introduction}

Seed dispersal is an important aspect of the ecology of plant communities. To aid dispersal, some plant species have evolved fleshy fruits around seeds (hereafter fruit plants), which are consumed for a nutritional reward by a wide variety of animals (Krefting and Roe, 1949; Hererra, 1984; Howe 1986; Willson, 1993). Through defecation, animals deposit the seeds at various distances from the source plant, called seed shadows, which are dependent on animal movements and gut retention times (Koike et al., 2010). Successful germination and seedling establishment within seed shadows is greatly affected by the microhabitat of the animal's defecation sites (Chavez-Ramirez and Slack, 1993), and sometimes secondary movements of seeds after defecation (Koike et al., 2012). By influencing the spatial distribution and demography of the plants they feed on, seed dispersers may shape the vegetative landscape and contribute to the natural regeneration of ecosystems (Wisz et al, 2013; Baños-Villalba et al., 2017). Most research on fruit dispersals has focused on birds, which are often considered the most important seed dispersers in tropical regions (Baños-Villalba et al., 2017; Corlett, 2017; Sebastián-González, 2017). However, in temperate or semi-arid regions, mammalian species were found to disperse seeds of fruit plants farther than birds, and at greater quantities (Jordano et al., 2007). In fact, some fruit plants may have evolved to have their seeds consumed exclusively by mammals instead of birds (Zhou et al., 2013). Among mammals, several species 
of omnivorous Carnivora have been shown to be major dispersers of seeds, including small and medium-sized Canidae (Willson et al., 1993). For example, coyotes (Canis latrans) were found to be the most highly frugivorous north temperate mammal, and this species is likely to be among the quantitatively most important mammalian dispersers of fruit plants in North America (Willson et al., 1993). Similarly, red foxes (Vulpes vulpes) and corsac foxes (V. corsac) were found to be important dispersers of fruit plants in semi-arid parts of southern Europe (Juan et al., 2006; Rosalino and Santos-Reis, 2009; Cancio et al., 2016) and central Asia (Murdoch et al., 2009), respectively.

In semi-arid regions of South Africa, there are three species of small and medium-sized canids that potentially could be major dispersers of fruit plants: cape foxes (Vulpes chama), bateared foxes (Otocyon megalotis), and black-backed jackals (Canis mesomelas). Although previous studies have confirmed that all three of these canid species regularly consume fruit (Kok, 1996; Klare et al., 2010, 2011, 2014; Kamler et al., 2012), their potential as important seed dispersers has received little attention. For example, bat-eared foxes, but not cape foxes and jackals, were reported to be a disperser of several species of fruit plants in semi-arid regions of South Africa (Milton and Dean, 2001). Only a few studies commented on the potential of blackbacked jackals to assist with seed dispersal of fruit plants (Castley et al., 2001; Kaunda and Skinner, 2003). Clearly, more research is needed on the potential of canids to act as seed dispersers in semi-arid environments in South Africa, given the propensity of canids to act as major seed dispersers in other semi-arid regions of the world. Such information might especially be relevant for South Africa, where large carnivores have been extirpated over most of the country, leaving jackals, which can attain high densities, as the dominant predator in most ecosystems (Klare et al.,. 2010; Minnie et al., 2016). 
The seed dispersal potential of canids in South Africa is relevant not only for the ecology of native fruit plants, but also for the ecology of alien mesquite (hybrids of Prosopis glandulosa and several other alien Prosopis spp.) which has invaded large areas of South Africa and is causing ecosystem-level changes in savannas (Dean et al., 2002; Milton et al., 2007; Shackleton et al., 2015; Van den Berg, 2010). In North America, coyotes were sometimes found to consume large amounts of honey mesquite ( $P$. glandulosa) seeds in semi-arid areas, and they acted as a major disperser of this species within its native range (Meinzer et al., 1975; McClure et al., 1995). In South America, the diet of the Sechuran fox (Lycalopex sechurae) in desert habitat was dominated by P. juliflora seeds in some seasons (Asa and Wallace, 1990), and it was found to be a relevant seed disperser of this species (Escribano-Avila, 2019). Thus, jackals or foxes might be helping to facilitate the dispersal and expansion of Prosopis spp. within its non-native range in South Africa, although the consumption of Prosopis seeds by canids in South Africa has never been reported.

The defecation sites of animals within their seed shadows can greatly affect successful germination and seedling establishment (Reid, 1989; Chavez-Ramirez and Slack, 1993). For example, it was concluded that red foxes and gray foxes (Urocyon cinereoargenteus) in Texas, USA, had deposited scats in poor germination sites because $>95 \%$ of the scats were found in open areas near or on dirt roads and trails where wildlife and livestock would trample them (Chavez-Ramirez and Slack, 1993). In contrast, scats deposited under the canopy of trees by other carnivores were considered favorable germination sites (Chavez-Ramirez and Slack, 1993). Similarly, coyotes in Oregon, USA, were found to defecate pinyon (Juniperus occidentalis) seeds in open areas, which are poor germination sites because pinyon seeds germinate best 
beneath shrubs (Schupp et al., 1997). Therefore, it is important to record information on the defecation sites when investigating the potential of canids to act as seed dispersers of fruit plants.

We describe the seasonal consumption of several species of fruit plants by cape foxes, bat-eared foxes, and black-backed jackals in South Africa. We also recorded information about their defecation sites to assess their potential as germination sites. This research was part of a larger study investigating the ecology of foxes and jackals; thus, the densities and home range sizes of the canid species on our study sites were known (Kamler et al., 2013b, 2017, 2019; Kamler and Macdonald, 2014). To estimate the seed dispersal potential of each canid species, we incorporated results about their fruit consumption and defecation sites, with information about their home range sizes and densities. This is the first detailed study of the seed dispersal potential of South African canids, and our results have relevance not only for the regeneration of native fruit plants in semi-arid regions, but also for the expansion of alien invasive Prosopis spp. as well.

\section{Materials and methods}

\subsection{Study species}

This research was part of a larger study investigating the ecology and interspecific relationships of cape foxes, bat-eared foxes, and black-backed jackals on several study sites in South Africa (Kamler et al. 2012, 2013b; Klare et al. 2010, 2011, 2014). Capture, radiotelemetry monitoring, and scat collection were the primary methods used to investigate the ecology of each species. Results of the ecological findings allowed us to make post hoc investigations of their potential as seed dispersers of fruit plants. A summary of the ecological findings of each species that are related to their potential as seed dispersers is shown in Table 1. 


\subsection{Study areas}

Research was conducted on two nature reserves near Kimberley in central South Africa from June 2005 to September 2007. The vegetation consists of elements of three major biomes converging there, Savanna, Nama Karoo, and Grassland biomes. Specific vegetation types included Kimberley Thorn Bushveld, Eastern Mixed Nama Karoo, and Dry Sandy Highveld Grassland (Mucina and Rutherford, 2006). This area has a semi-arid continental climate, with a mean annual rainfall of $419 \pm 134 \mathrm{~mm}$ (Kamler et al., 2012). There is a distinct cold and dry period during winter months $\left(-8^{\circ}\right.$ to $\left.25^{\circ} \mathrm{C}\right)$, and a hot and rainy period during summer months $\left(8^{\circ}\right.$ to $40^{\circ} \mathrm{C}$ ). All large carnivores in the area had been extirpated by humans prior to 1900 . Benfontein Nature Reserve $\left(110 \mathrm{~km}^{2}\right)$, formerly Benfontein Game Farm (hereafter Benfontein), was located on the border of the Northern Cape and Free State provinces (28 $51^{\prime} \mathrm{S}$, $24^{\circ} 48^{\prime}$ E), approximately $10 \mathrm{~km}$ south of Kimberley. This site was dominated by Eastern Mixed Nama Karoo vegetation (at least $60 \%$ of study site), and was managed primarily for three wild ungulate species, springbok (Antidorcas marsupialis), blesbok (Damaliscus dorcas), and black wildebeest (Connochaetes gnou), as well as a small herd of cattle (Bos taurus). In addition to the canids, other carnivore species present included aardwolves (Proteles cristatus), caracals (Caracal caracal), African wild cats (Felis silvestris), black-footed cats (Felis nigripes), smallspotted genets (Genetta genetta), striped polecats (Ictonyx striatus), and at least 5 species of Herpestidae (Kamler et al., 2012). Aside from one or two annual culls for ungulates on Benfontein, there was relatively little human activity. No carnivore species was heavily persecuted on Benfontein during the study, although jackals were infrequently and 
opportunistically shot during culling operations for ungulates $(<3$ jackals/year during the study; Kamler et al., 2012).

Rooipoort Nature Reserve $\left(420 \mathrm{~km}^{2}\right.$; hereafter Rooipoort) was located ca. $50 \mathrm{~km}$ west of Kimberley in the Northern Cape Province (28³9'S; $\left.24^{\circ} 11^{\prime} \mathrm{E}\right)$. Rooipoort was dominated by Kimberley Thorn Bushveld (at least $60 \%$ of study site), and also included riverine habitat along the Vaal River. Rooipoort was managed primarily for safari hunting and contained at least 15 species of ungulates. Brown hyenas (Hyaena brunnea) occurred on Rooipoort, along with all the smaller carnivore species that were found on Benfontein (Klare et al., 2010). As a reserve policy, no carnivore species was persecuted.

\subsection{Consumption of fruits and seed shadows}

We determined food habits, including consumption of fruit, by analysis of scats (i.e., droppings). For jackals, scats were collected by seasonally walking transects established on both Benfontein and Rooipoort (for details see Klare et al. 2010). For cape foxes and bat-eared foxes, too few scats were collected along transects, so additional collections were made each season around their den sites on Benfontein. Scats were classified to species based on size and shape (Walker, 1996). Seasons were defined as spring (Sep - Nov), summer (Dec - Feb), autumn (Mar - May), and winter (Jun - Aug), to parallel major changes in climate and corresponding changes in food resources. To obtain adequate sample sizes (37-93 scats/species) for each season, scats were pooled across years. The sample size of scats for cape foxes in summer was too low ( $\mathrm{n}<15$ scats), thus this season was excluded from analyses. Following collection, scats were processed in a laboratory to identify prey items (for more details see Klare et al. 2010). We weighed the dried remains from each scat, and visually estimated volume of each undigested food item in the 
scat to the nearest $5 \%$, and presented results as percent volume (i.e., percentage of the total volume of a given prey category compared to the total volume of all food items). We also calculated ingested biomass based on the weight of dried remains using correction factors provided by Goszczynski (1974) supplemented with those from Jedrzejewska and Jedrzejewski (1998). Finally, we also calculated the frequency of occurrence of the different prey categories (i.e., percentage of scats containing at least traces of a food category). We grouped prey species into 10 taxonomic-ecological categories (for details see Klare et al. 2010), one of which was fruit. The seeds were identified to fruit species based on a comparison to a reference collection. The complete dietary results of the other food categories were reported in previous studies (Klare et al., 2010, 2011, 2014), therefore only the results concerning fruit consumption are reported in this paper.

For each canid species, the $\mathrm{kg}$ of fruit consumed per area $\left(\mathrm{km}^{2}\right)$ during each season was calculated according to a formula modified from Klare et al. (2010): $\mathrm{F}_{\mathrm{kg}}=\mathrm{DFI} \times \mathrm{B}_{\text {fruit }} \times \mathrm{N}_{\text {days }} \mathrm{x}$ $\mathrm{D}$, where $\mathrm{F}_{\mathrm{kg}}$ is the $\mathrm{kg}$ of fruit consumed per $\mathrm{km}^{2}$, DFI the daily food intake, $\mathrm{B}_{\text {fruit }}$ the fraction of a given fruit in the total ingested biomass, $\mathrm{n}_{\text {days }}$ the number of days per season, and $\mathrm{D}$ is the density of each canid species. We assumed the daily food intake was $8.5 \%$ of the body mass of each canid species, given that carnivores are assumed to consume food equaling $7-10 \%$ of their body mass per day (Mukherjee et al. 2004). Based on the mean body mass values for each canid species in our study (Table 1), the daily food intake was estimated to be $0.25 \mathrm{~kg}$ for cape foxes, $0.32 \mathrm{~kg}$ for bat-eared foxes, and $0.77 \mathrm{~kg}$ for jackals. The density of canid species was taken from Table 1 . The annual $\mathrm{kg}$ of fruit consumed per $\mathrm{km}^{2}$ was calculated by summing the results from each season. Because the diet of cape fox was not determined in summer, we took the average of biomass consumed for the other three seasons as a substitute value for summer. 
Seed shadows are dependent on animal movements and gut retention times (Koike et al., 2010). Although we did not determine gut retention times for the species on our study sites, gut retention times have been calculated in previous studies for small and medium-sized canids. The gut retention time for black-backed jackals was 1-5 days when fed small rodents (Bowland and Bowland, 1991). When fed different fruits, the gut retention time was 4-48 hr for arctic foxes (Vulpes lagopus; Graae et al., 2004), and 2-36 hr, with of mean of 7-8 hr, for pampas foxes (Lycalopex gymnocercus) and crab-eating foxes (Cerdocyon thous; Varela and Bucher, 2006). A typical radio-tracking session in our study was 6-8 hr (Kamler et al., 2012), and during this period individuals of all three canid species could transverse the diameter of their home ranges. Therefore, we used the mean home-range sizes of each canid species (Table 1) as a proxy for their potential seed shadows, and assumed that after they consumed fruit, then they could defecate the seeds anywhere within their home ranges within 6-8 hr.

Previous research showed that shorter gut retention times can positively affect the germination of seeds consumed by canids, because less exposure of seeds to gastrointestinal enzymes reduces seed damage (Howe, 1986; Cypher and Cypher, 1999). Passage rates of seeds from meals consisting entirely of fruit are likely to be more rapid due to the presence of laxatives in fruit (Murray et al., 1994). Consequently, fruit seeds can have higher germination rates if they are deposited in scats consisting almost entirely of fruit seeds (Cypher and Cypher, 1999). Therefore, following Cypher and Cypher (1999), we classified scats of each canid species as "fruit-meal" if they comprised $>90 \%$ seeds.

\subsection{Defecation sites}


In semi-arid habitats, germination of seeds and herbaceous cover was found to be higher under canopies compared to open areas because of the microclimates provided by the canopies, which includes greater concentrations of organic matter and reduced temperatures and evapotranspiration due to the shade (Belsky et al., 1993; Verdú and García-Fayos, 1996). For example, in semi-arid savannas of South Africa, fleshy-fruited plants occur predominantly under tree canopies, and far less in open areas, because frugivorous birds perch in the tree limbs and because the subcanopy microsite conditions are favorable for seed germination and seedling establishment (Milton et al., 2007). Therefore, to estimate germination potential of consumed seeds in our study, we collected detailed information on the microsites where scats were deposited. When walking transects along dirt tracks or collecting scats by dens or resting sites, we recorded whether the scats were deposited: 1) on dirt tracks with no shade; 2) on open ground with no shade; 3) on a tall tuft of grass with little or no shade, or; 4) under a bush or large shrub with shade. We also recorded how many scats were deposited at each defecation site. We classified defecation sites as having no germination potential if they were deposited on dirt tracks where they were easily trampled by vehicles or wildlife, low germination potential if they were deposited on open ground (not including dirt tracks) and tufts of grass, and high germination potential if they were deposited under bushes or shrubs with shade. Although the shade provided by bushes and shrubs likely does not have the same favorable microclimates for seed germination as trees with larger canopies, we assumed they were more favorable to seed germination than open ground. Scats in open ground were more visible that scats on or beneath small shrubs, which could have biased our results. However, to reduce this bias we thoroughly searched all small shrubs and bushes along our scat transect lines. Additionally, most dens and 
day rest sites of the foxes were in thick vegetation to aid their concealment, thus we thoroughly searched both barren ground and small shrubs and bushes at these sites as well.

\section{Results}

On Benfontein, we collected 133 cape fox scats, 177 bat-eared fox scats, and 312 jackal scats. All canid species consumed fruit of Diospyros lycioides (bluebush) in every season, although frequency of consumption peaked in different seasons for each canid species: summer for bat-eared foxes, autumn for jackals, and winter for cape foxes (Table 2, Fig. 1). Overall, bateared foxes consumed $D$. lycioides fruit most frequently (14-42\% of scats across seasons), followed by cape foxes (5-18\%) and jackals (5-16\%; Table 2). Jackals, but neither fox species, consumed Prosopis fruit, with peak consumption in summer (Table 2, Fig. 1). No other species of fruit plants were detected in scats. Based on home-range sizes, the potential seed shadow was highest for cape foxes, followed by jackals and bat-eared foxes (Table 1).

On Rooipoort, we collected 522 scats from black-backed jackals, but none from either fox species. Jackals consumed at least three fruit species on Rooipoort, and frequency of consumption peaked in different seasons for each fruit: Grewia flava (velvet raisin or brandybush) in summer, Diospyros lycioides in autumn, and Ziziphus mucronata (buffalo thorn) in winter (Table 2, Fig. 2). The most frequently consumed fruit on Rooipoort was Z. mucronata (9-82\% across seasons), followed by G. flava (3-46\%) and D. lycioides (4-40\%; Table 2, Fig. 2).

On Benfontein, when taking into account daily food intake and canid densities, the annual consumption of fruit per area was $52.2 \mathrm{~kg} / \mathrm{km}^{2}$ for bat-eared foxes (3.4-22.6 across seasons), $5.5 \mathrm{~kg} / \mathrm{km}^{2}$ for jackals (0.3-3.0 across seasons), and $0.5 \mathrm{~kg} / \mathrm{km}^{2}$ for cape foxes $(<0.1-0.3$ across seasons; Table 2). Overall, jackals on Benfontein consumed similar amounts of Prosopis 
$\left(2.9 \mathrm{~kg} / \mathrm{km}^{2}\right)$ and Diospyros lycioides fruit $\left(2.6 \mathrm{~kg} / \mathrm{km}^{2}\right)$ annually per area (Table 2). On

Rooipoort, the annual consumption of fruit per area was $48.8 \mathrm{~kg} / \mathrm{km}^{2}$ for jackals $(3.4-20.5$ across seasons; Table 2). Overall, jackals on Rooipoort consumed 4-5 times as much Ziziphus mucronata fruit annually per area $\left(32.3 \mathrm{~kg} / \mathrm{km}^{2}\right)$, than either Grewia flava $\left(8.8 \mathrm{~kg} / \mathrm{km}^{2}\right)$ or $D$. lycioides $\left(7.6 \mathrm{~kg} / \mathrm{km}^{2}\right.$; Table 2$)$.

For cape foxes, $50.0 \%$ of scats containing Diospyros lycioides seeds were fruit-meals, whereas for bat-eared foxes only $28.3 \%$ of scats containing D. lycioides seeds were fruit-meals. For jackals on Benfontein, fruit-meals comprised $48.1 \%$ of scats containing D. lycioides seeds, and $63.3 \%$ of scats containing Prosopis seeds. For jackals on Rooipoort, fruit-meals comprised $37.7 \%$ of scats containing D. lycioides seeds, $52.1 \%$ of scats containing Ziziphus mucronata seeds, and $53.4 \%$ of scats containing Grewia flava seeds.

Of all the cape fox scats collected, $51.1 \%$ were classified as no germination sites because they were deposited on dirt tracks where seeds could be trampled by vehicles and wildlife. The remaining cape fox scats $(48.9 \%)$ were classified as poor germination sites because they were deposited on open ground near their den sites or resting sites. All defecation sites of cape foxes contained a single scat. Of all the bat-eared fox scats collected, $100 \%$ were classified as poor germination sites because all were deposited on open ground near den sites or resting sites. All defection sites of bat-eared foxes contained single scats, although there were often multiple single scats deposited over small areas near group resting sites. Of 384 jackal scats, $51.6 \%$ were classified as good germination sites because scats were deposited on bushes or shrubs, typically near dirt tracks or trails. Scats deposited on bushes or shrubs eventually fell to the ground, where the fruit seeds were provided shade. The remainder of the jackal scats were classified as poor germination sites $(27.9 \%)$ because they were deposited on tufts of grass, or no germination sites 
(19.5\%) because they were deposited on dirt tracks. The defecation sites of jackals consisted of 1 scat $(72.7 \%), 2$ scats $(18.2 \%), 3$ scats $(9.1 \%)$, or $4-8$ scats $(4.4 \%)$.

\section{Discussion}

Both fox species and jackals consumed Diospyros lycioides berries on Benfontein throughout the year, indicating all three canid species are potential dispersers of this fruit. Previous research also showed that all three canid species frequently consumed D. lycioides berries (Kok, 1996). Reasons for the different seasonal peaks in consumption among canids on Benfontein were unclear, but may have been related to periods of fruiting and availability of main prey. Previous research on canids showed that consumption of fruits typically peaked when fruits were most ripe (Chavez-Ramirez and Slack, 1993; Kamler et al., 2002, 2007, 2014; Murdoch et al., 2009). In southern Africa, D. lycioides starts fruiting in mid-summer and peaks in autumn (Mujuru, 2011), at which time ripe berries commonly fall on the ground. However, some old berries of D. lycioides can stay on the tree till spring (Mujuru, 2011), which helps explain why $D$. lycioides berries were consumed year around by all three canid species. Nevertheless, it appears that jackals most frequently consumed $D$. lycioides during the peak fruiting season in autumn. For bat-eared foxes, their main prey on Benfontein was northern harvester termites (Hodotermes mossambicus; Klare et al., 2011), whose peak availability is autumn and winter (Coaton, 1958). Thus, consumption of D. lycioides berries may have peaked in summer for bat-eared, just as this shrub was beginning to fruit, because their main prey was less available during that season. Similarly, $D$. lycioides berries may have been important buffer food for cape foxes in winter, when small rodents, their main prey (Klare et al., 2011), were presumably less available. 
Prosopis fruit was consumed by jackals, but not foxes, on Benfontein, indicating that only jackals are potential dispersers of this species on our study site. Reasons for species-specific consumption of Prosopis fruit by canids was not clear, but could have been due to dietary preferences (Macdonald, 1977). For example, within the native range of $P$. glandulosa in North America, previous research showed that coyotes consumed P. glandulosa fruit but sympatric kit foxes (Vulpes macrotis) did not (List et al., 2003), perhaps indicating that medium-sized Canis species likely have a higher preference for this fruit compared to foxes. On Benfontein, jackals consumed Prosopis fruit primarily in summer, when this species fruits, and rarely consumed it during other seasons, in contrast to Diospyros lycioides. Interestingly, we did not detect consumption of native Acacia spp. (A. tortilis and A. erioloba) by jackals on Benfontein, even though both Acacia and Prosopis species were relatively common on Benfontein. In South Africa, alien invasive Prosopis appears to be transforming savannas by overtopping native trees such as Acacia, with birds acting as major dispersers of Prosopis (Milton et al., 2007; Shackleton et al., 2015). Our results indicate that jackals are probably major dispersers of Prosopis, and the preferential consumption of Prosopis by jackals might be helping to give Prosopis a dispersal advantage over Acacia, possibly due to the greater edibility or palatability of Prosopis fruit and pods.

On Rooipoort, jackals consumed more fruits throughout the year, and consumed more fruit species, compared to Benfontein. These differences were likely due to habitat, as Rooipoort is dominated by bushveld habitat, whereas Benfontein is dominated by Nama Karoo. Different seasonal peaks in consumption by jackals likely reflected the different peak fruiting seasons for each species. Consumption of Prosopis by jackals was not detected on Rooipoort because this alien invasive had not yet colonized this site. Jackal consumed more Ziziphus mucronata 
compared to the other fruits, as frequency of consumption was $>70 \%$ during autumn and winter, whereas frequency of the other fruits were 3-46\% throughout the year. Although previous studies showed that jackals sometimes consumed Z. mucronata fruit (Kok, 1996; Kaunda and Skinner, 2003), our study is the first to show that Z. mucronata fruit was a major part of the jackal diet. Similarly, our study is the first to show such high consumption of Grewia flava fruit by jackals, although consumption of Grewia spp. fruit in small amounts was reported in previous studies (Bothma, 1966, 1971; Kok, 1996; Kaunda and Skinner, 2003). In Botswana, Kaunda and Skinner (2003) found jackals consumed Grewia spp. fruit in most seasons, and suggested that jackal defecation activities were contributing to the dispersal of this species on a nature reserve. In South Africa, Z. mucronata, G. flava, and Diospyros lycioides are all considered encroaching woody species (Mureva and Ward, 2016; Madibo, 2017), thus the high consumption of these fruits by jackals might be helping to disperse and spread these species in semi-arid areas of the country. Although Acacia spp. were more common on Rooipoort than Z. mucronata, G. flava, and D. lycioides (Bezuidenhout, 2009), Acacia tortilis seeds were found in only 2 of 522 jackal scats, and only comprised 5\% of those scats. This indicates that Acacia seeds are seldom consumed by jackals, even when Acacia spp. are relatively abundant, and that jackals might be giving a dispersal advantage to Z. mucronata, G. flava, and D. lycioides over Acacia.

The seed dispersal potential of cape foxes appeared to be lowest among all three canid species. Although cape foxes had the largest potential seed shadow, this species had the lowest density and lowest consumption of fruit per area. Additionally, all cape fox scats that we recorded were deposited on either trails or open ground, where seeds had no or low germination potential, respectively. Bat-eared foxes appeared to have moderate seed dispersal potential, because this species they had the highest density and high consumption of fruit per area. 
However, bat-eared foxes had the smallest potential seed shadow. Additionally, only $28 \%$ of bateared fox scats containing seeds were fruit-meals. The latter suggests that Diospyros lycioides seeds in bat-eared fox scats potentially had lower germination rates compared to cape foxes and jackals, both of which had higher frequencies (48-50\%) of D. lycioides fruit-meals. Furthermore, bat-eared fox scats we recorded were deposited on open ground where seeds had low germination potential.

Jackals had the highest seed dispersal potential of all canid species, although there were differences between sites. On Benfontein, jackals had only moderate potential seed shadow. However, jackals went on nightly extraterritorial forays more often than foxes (up to $20 \%$ of the time), and much further than foxes (up to $8 \mathrm{~km}$ from home range boundaries; Kamler et al. 2019), indicating jackals might have had the largest potential seed shadow in our study, despite their moderate home-range size. Our results are consistent with previous research in southern Africa, which showed that jackals moved on average $12 \mathrm{~km}$ per day (Furguson et al., 1983), and that jackals can deposit scats up to $30 \mathrm{~km}$ from where the meals were consumed (Jenner et al., 2011). Compared to foxes, jackals on Benfontein had moderate densities and moderate consumption of fruit per area. In contrast, on Rooipoort, jackals had higher densities and high consumption of fruit per area. On both sites, most jackal scats were deposited on bushes and shrubs where fallen seeds had some shade and protection and presumably high germination potential. Our results were consistent with previous research that showed black-backed jackal defecate on elevated conspicuous objects, including tufts of grass, large rocks, and elephant dung, to amplify their territorial markings (Ferguson et al., 1983; Hayward and Hayward, 2010). This is in contrast to coyotes and some fox species that defecate on dirt tracks and other flat open areas (Chavez-Ramirez and Slack, 1993; Schupp et al., 1997; Kamler et al., 2002, 2007), 
although red foxes often mark on elevated conspicuous objects (Macdonald, 1980). In the absence of elephant dung and large rocks, jackals on our study sites preferentially defecated on bushes and shrubs, apparently because these were some of the only elevated surfaces that were available. This marking behavior may have inadvertently provided consumed fruit seeds with favorable germination sites, because seeds that fell from scats were provided shade. Additionally, 27\% of scats were deposited with other scats in latrines or middens (Macdonald, 1979), suggesting many seeds had additional nutrients for growth provided by the dung (Howe and Smallwood, 1982). However, further research is needed to test whether the microsites of jackal defecations have higher seedling survival compared to open ground.

A major limitation of our study is that we did not determine germination rates of seeds in the scats deposited by foxes and jackals, thus the ultimate fate of the consumed seeds was unknown. Therefore, our results should be viewed with caution because we can only describe seed dispersal potential, and not the actual germination success of the dispersed seeds. Previous research showed that seeds from fleshy fruits germinated from bat-eared fox scats (Milton and Dean, 2001) and we observed seedlings germinating from some of the jackal scats we collected, indicating germination of consumed seeds did occur in our study site. Additionally, germination of seeds in canid scats has been investigated in several previous studies. In general, the pulp removal and seed scarification that occurs when canids consume fruit has been shown to improve germination rates or increase seedling quality over non-consumed seeds (Juan et al., 2006; Varela and Bucher, 2006; Cazetta and Galetti, 2009; Rosalino et al., 2010; Rebein et al., 2017; Escribano-Avila, 2019) although results can vary depending on the fruit species (Cypher and Cypher, 1999). And in contrast to ungulates (Bodmer, 1991), seeds consumed by canids are generally defecated whole, because very few are destroyed during mastication and digestion 
(Herrera, 1989; Chavez-Ramirez and Slack, 1993). Additionally, we found that most scats of jackals and cape foxes that contained seeds were fruit-meals, indicating that passage rates of seeds through the gastrointestinal tracts were relatively fast (Murray et al., 1994) which also promotes higher germination rates (Cypher and Cypher, 1999). Regardless of differences in germination rates between consumed and unconsumed seeds, a greater advantage provided by the canids was likely the movement of seeds away from the parent plant because this action alone provides significant benefits to seeds (Traveset and Willson 1997; Cypher and Cypher, 1999), such as reducing competition with parent plants and siblings, and reducing potential for inbreeding (Howe and Smallwood, 1982). Thus, jackals and foxes might be ideal dispersers for several fruit plants in semi-arid regions of South Africa. Other sympatric carnivores appear to be less well adapted for dispersing seeds in the region, because small and medium-sized felids do not consume fruit at all (Bowland and Perrin, 1993; Herbst and Mills, 2010; Braczkowski et al., 2012; Kamler et al., 2015), and aardwolves (Proteles cristata) consume much less fruit than foxes and jackals (Kok, 1996). Smaller carnivores such as herpestids, viverrids, and mustelids sometimes, but not always, consume fruit in South Africa (du Toit, 1980; Avenant and Nel, 1997; Larivière, 2002), but their smaller body sizes (0.4-3.3 kg) and corresponding smaller home ranges (0.1-2.8 $\mathrm{km}^{2}$; Maddock, 1988) preclude them from consuming large amounts of fruit per area and having large seed shadows, at least compared to canids. Other mammals that might be important dispersers of fruit plants are primates, such as chacma baboons (Papio ursinus; Slater and du Toit, 2002; Tew et al., 2018), but their numbers are relatively low or absent in most of the semi-arid habitats of South Africa (Skinner and Chimimba, 2005).

Cape foxes, bat-eared foxes, and jackals have occupied southern Africa for at least 2.5 million years, and possibly up to 5 million years ago (Kamler et al., 2012). Therefore, it is 
possible that coevolutionary relationships developed between native fruit plants and these canid species, especially given the extent to which fruit seeds were consumed and moved over large areas by these canids. However, pair-wise coevolution between specific fruit plants and animal dispersers is relatively rare (McKey, 1975; Howe, 1986; Cypher and Cypher, 1999) and consequently seeds of fleshy fruit plants are usually dispersed by a suite of animal species (Howe and Smallwood, 1982). For example, in North America dispersal relationships between plants and animals are usually unspecified, although generalist feeders such as coyotes can became major and important dispersers for several different fruit plants (Willson, 1993). The same is likely true in southern Africa, where jackals and cape foxes are generalist feeders (Klare et al., 2010, 2014), yet it appears that they are important dispersers for several fruit plants when fruits are consumed in high quantities. The bat-eared fox is a specialized feeder on termites, for which it has several unique adaptations (Klare et al., 2011), although this species, too, appears to be an important disperser for fruit plants when they consume fruits as buffer food in high quantities.

\section{Conclusions}

In semi-arid savanna and shrubland of South Africa, seed dispersal of fruit plants by foxes and jackals is probably more significant than previously thought, especially given that bateared foxes and jackals each consumed and dispersed about $50 \mathrm{~kg}$ of fruit $/ \mathrm{km}^{2}$. Compared to other mammalian species in semi-arid habitats, canids, especially jackals, attain relatively high densities, consume relatively large amounts of fruits, and have relatively large home ranges and movements, all of which facilitates dispersal of seeds from fruit plants. Additionally, the microhabitat of most defecation sites of jackals would seemingly promote germination of seeds. Similar to that concluded for coyotes in North America, jackals potentially are the most 
important seed dispersing mammal of semi-arid regions of South Africa, especially in areas where large carnivores have become extirpated and jackals are abundant and dominant predators. Consequently, jackals likely are important for the regeneration of several native fruit plants in South Africa, and their selective consumption of Prosopis fruit might be facilitating the spread of this alien invasive plant in semi-arid savannas and shrublands.

\section{Acknowledgments}

We thank De Beers Consolidated Mines for allowing us access to their properties, and providing support for this project. We also thank U. Stenkewitz for help with collecting scats, B. Wilson and McGregor Museum for providing logistical support, and an anonymous reviewer for helpful comments that improved the manuscript. Funding for JFK was provided by a Research Fellowship from the Wildlife Conservation Society, New York, and a Marie Curie Fellowship for the European Commission, Brussels, Belgium.

\section{References}

Asa, C.S., Wallace, M.P., 1990. Diet and activity of the Sechuran desert fox (Dusicyon sechurae). J. Mammal. 71, 69-72.

Avenant, N.L., Nel, J.A.J., 1997. Prey use by four syntopic carnivores in a strandveld ecosystem. S. Afr. J. Wildl. Res. 27, 86-93.

Baños-Villalba, A., Blanco, G., Díaz-Luque, J.A., Dénes, F.V., Hiraldo, F., Tella, J.L., 2017. Seed dispersal by macaws shapes the landscape of an Amazonian ecosystem. Sci. Rep. 7, 7373.

Belsky, A.J., Mwonga, S.M., Amundson, R.G., Duxbury, J.M., Ali, A.R., 1993. Comparative 
effects of isolated trees on their undercanopy environments in high- and low-rainfall savannas. J. Appl. Ecol. 30, 143-155.

Bezuidenhout, H., 2009. The classification, mapping and description of the vegetation of the Rooipoort Nature Reserve, Northern Cape, South Africa. Koedoe 51, 695.

Bodmer, R.E., 1991. Strategies of seed dispersal and seed predation in Amazonian ungulates. Biotropica 23, 255-261.

Bothma, J.D.P., 1966. Notes of the stomach contents of certain Carnivora (Mammalia) from the Kalahari Gemsbok Park. Koedoe 9, 37-39.

Bothma, J.D.P., 1971. Food of Canis mesomelas in South Africa. Zool. Afr. 6, 195-203.

Bowland, J.M., Bowland, A.E., 1991. Differential passage rates of prey components through the gut of serval Felis serval and black-backed jackal Canis mesomelas. Koedoe 34, 37-39.

Bowland, J.M., Perrin, M.R., 1993. Diet of serval Felis serval in a highland region of Natal. S. Afr. J. Zool. 28, 132-135.

Braczkowski, A., Watson, L., Coulson, D., Lucas, J., Peiser, B., Rossi, M., 2012. The diet of caracal, Caracal caracal, in two areas of the southern Cape, South Africa as determined by scat analysis. S. Afr. J. Wildl. Res. 42, 111-116.

Cancio, I., González-Robles, A., Bastida, J.M., Manzaneda, A.J., Salido, T., Rey, P.J., 2016. Habitat loss exacerbates regional extinction risk of the keystone semiarid shrub Ziziphus lotus through collapsing the seed dispersal service by foxes (Vulpes vulpes). Biodivers. Conserv. 25, 693-709.

Castley, J.G., Bruton, J.-S., Kerley, G.I.H., McLachlan, A., 2001. The importance of seed dispersal in the Alexandia Coastal Dunefield, South Africa. J. Coast. Conserv. 7, 57-70.

Cazetta, E., Galetti, M., 2009. The crab-eating fox (Cerdocyon thous) as a secondary seed 
disperser of Eugenia umbelliflora (Myrtaceae) in a Restinga forest of southeastern Brazil. Biolta Neotrop. 9, 271-274.

Chavez-Ramirez, F., Slack, R.D., 1993. Carnivore fruit-use and seed dispersal of two selected plant species of the Edwards Plateau, Texas. Southwest. Nat. 38, 141-145.

Coaton, W.G.H., 1958. The hodotermitidae harvester termites of South Africa. Dept. Agr. Sci. Bull. 375, Entomol. Ser. 43:1-112.

Corlett, R.T., 2017. Frugivory and seed dispersal by vertebrates in tropical and subtropical Asia: an update. Glob. Ecol. Conserv. 11, 1-22.

Cypher, B.L, Cypher, E.A., 1999. Germination rates of tree seeds ingested by coyotes and raccoons. Am. Midl. Nat. 142, 71-76.

Dean, W.R.J., Anderson, M.D., Milton, S.J., Anderson, T.A., 2002. Avian assemblages in native Acacia and alien Prosopis drainage line woodland in the Kalahari, South Africa. J. Arid. Environ. 51, 1-19.

du Toit, C.F., 1980. The yellow mongoose Cynictis penicillata and other small carnivores in the Mountain Zebra National Park. Koedoe 23, 179-184.

Escribano-Avila, G., 2019. Non-specialized frugivores as key seed dispersers in dry disturbed environments: An example with a generalist neotropical mesocarnivore. J. Arid Environ. $167,18-25$.

Ferguson, J.W.H., Nel, J.A.J., de Wet, M.J., 1983. Social organization and movement patterns of black-backed jackals Canis mesomelas in South Africa. J. Zool. (Lond.) 199, 487-502.

Goszczyński, J., 1974. Studies on the food of foxes. Acta Theriol. 19, 1-18

Graae, B.J., Pagh, S., Bruun, H.H., 2004. An experimental evaluation of the arctic fox (Alopex lagopus) as a seed disperser. Arct. Antarct. Alp. Res. 36, 468-473. 
Hayward, M.W., Hayward, G.J., 2010. Potential amplification of territorial advertisement markings by black-backed jackals (Canis mesomelas). Behaviour 147, 979-992.

Herbst, M., Mills., M.G.L., 2010. The feeding habits of the southern African wildcat, a facultative trophic specialist, in the southern Kalahari (Kgalagadi Transfrontier Park, South Africa/Botswana). J. Zool. (Lond.) 280, 403-413.

Herrera, C.M., 1984. A study of avian frugivores, bird-dispersed plants, and their interaction in Mediterranean scrublands. Ecol. Monogr. 54, 1-23.

Herrera, C.M., 1989. Frugivory and seed dispersal by carnivorous mammals, and associated fruit characteristics, in undisturbed Mediterranean habitat. Oikos 55, 250-262.

Howe, H.F., 1986. Seed dispersal by fruit-eating birds and mammals. In: Murray, D.R. (Ed.), Seed Dispersal. Academic Press, New York, USA, pp. 123-189.

Howe, H.F., Smallwood, J., 1982. Ecology of seed dispersal. Ann. Rev. Ecol. Syst. 13, 201-223. Jedrzejewska, B., Jedrzejewski, W., 1998. Predation in vertebrate communities: the Białowieża Primeval Forest as a case study. Springer-Verlag, Heidelberg, Germany.

Jenner, N., Groombridge, J., Funk, S.M., 2011. Commuting, territoriality and variation in group and territory size in a black-backed jackal population reliant on a clumped, abundant food resource in Namibia. J. Zool. (Lond.) 284, 231-238.

Jordano, P., García, C., Godoy, J.A., García-Castaño, J.L., 2007. Differential contribution of frugivores to complex seed dispersal patterns. Proc. Natl. Acad. Sci. Unit. States Am. $104,3278-3282$.

Juan, T., Sagrario, A., Jesus, H., Cristina, C.M., 2006. Red fox (Vulpes vulpes L.) favour seed dispersal, germination and seedling survival of Mediterranean hackberry (Celtis australis L.). Acta Oecol. 30, 39-45. 
Kamler, J.F., Ballard, W.B., Wallace, M.C., Gipson, P.S., 2007. Diets of swift foxes in continuous and fragmented prairie in northwestern Texas. Southwest. Nat. 52, 504-510.

Kamler, J.F., Gipson, P.S., Perchellet, C.C., 2002. Seasonal food habits of coyotes in northeastern Kansas. Prairie Nat. 34, 75-83.

Kamler, J.F., Gray, M.M., Oh, A., Macdonald, D.W., 2013a. Genetic structure, spatial organization, and dispersal in two populations of bat-eared foxes. Ecol. Evol. 3, 28922902.

Kamler, J.F., Klare, U., Ballard, W.B., Wallace, M.C., Gipson, P.S., 2014. Comparison of coyote diets in continuous and fragmented short-grass prairie in the Texas Panhandle. Tex. J. Sci. 66, 25-41.

Kamler, J.F., Macdonald, D.W., 2014. Social organization, survival, and dispersal of cape foxes (Vulpes chama) in South Africa. Mamm. Biol. 79, 64-70.

Kamler, J.F., Rostro-García, S., Macdonald, D.W., 2017. Seasonal changes in social behavior and movements of bat-eared foxes in South Africa: disease implications. J. Mammal. 98, 1426-1433.

Kamler, J.F., Stenkewitz, U., Gharajehdaghipour, T., Macdonald, D.W., 2019. Social organization, home ranges, and extraterritorial forays of black-backed jackals. J. Wildl. Manage. 83, 1800-1808.

Kamler, J.F., Stenkewitz, U., Klare, U., Jacobsen, N.F., Macdonald, D.W., 2012. Resource partitioning among cape foxes, bat-eared foxes, and black-backed jackals in South Africa. J. Wildl. Manage. 76, 1241-1253.

Kamler, J.F., Stenkewitz, U., Macdonald, D.W., 2013b. Lethal and sublethal effects of blackbacked jackals on cape foxes and bat-eared foxes. J. Mammal. 94, 295-306. 
Kamler, J.F., Stenkewitz, U., Wilson, B., Herrick, J., Lamberski, N., Sliwa, A., Macdonald, D.W., 2015. Ecological relationships of black-footed cats (Felis nigripes) and sympatric canids in South Africa. Mamm. Biol. 80, 122-127.

Kaunda, S.K.K., Skinner, J.D., 2003. Black-backed jackal diet at Mokolodi Nature Reserve, Botswana. Afr. J. Ecol. 41, 39-46.

Klare, U., Kamler, J.F., Macdonald, D.W., 2011. The bat-eared fox: A dietary specialist? Mamm. Biol. 76, 646-650.

Klare, U., Kamler, J.F., Macdonald, D.W., 2014. Seasonal diet and numbers of prey consumed by Cape foxes Vulpes chama in South Africa. Wildl. Biol. 20, 190-195.

Klare, U., Kamler, J.F., Stenkewitz, U., Macdonald, D.W., 2010. Diet, prey selection, and predation impact of black-backed jackals in South Africa. J. Wildl. Manage. 74, 10301042.

Koike, S., Masaki, T., Nemoto, Y, Kozakai, C., Yamazaki, K., Kasai, S., Nakajima, A., Kaji, K., 2010. Estimate of the seed shadow created by the Asiatic black bear Ursus thibetanus and its characteristics as a seed disperser in Japanese cool-temperate forest. Oikos 120, 280290.

Koike, S., Morimoto, H., Kozakai, C., Arimoto, I., Yamazaki, K., Iwaoka, M., Soga, M., Koganezawa, M., 2012. Seed removal and survival in Asiatic black bear Ursus thibetanus faeces: effects of rodents as secondary seed dispersers. Wildl. Biol. 18, 24-34.

Kok, O.B., 1996. Dieetsamestelling van enkele karnivoorsoorte in die Vrystaat, Suid-Afrika. S. Afr. J. Sci. 92, 393-398. [In Afrikaans with English summary]

Krefting, L. W., Roe, E.I., 1949. The role of some birds and mammals in seed germination. Ecol. Monogr. 19, 271-286. 
Larivière, S., 2002. Ictonyx striatus. Mamm. Species 698, 1-5.

List, R., Manzano-Fischer, R., Macdonald, D.W., 2003. Coyote and kit fox diets in prairie dog towns and adjacent grasslands in Mexico. In: Sovada, M.A., Carbyn, L. (Eds.), The Swift Fox: Ecology and Conservation of Swift Foxes in a Changing World. Canadian Plains Research Center, University of Regina, Canada, pp. 183-188.

Macdonald, D.W., 1977. On food preference in the red fox. Mammal Rev. 7, 7-23.

Macdonald, D.W., 1979. The flexible social system of the golden jackal, Canis aureus. Behav. Ecol. Sociobiol. 5, 17-38.

Macdonald, D.W., 1980. Patterns of scent marking with urine and faeces amongst carnivore communities. Symp. Zool. Soc. Lond. 45, 107-139.

Maddock, A.H., 1988. Resource Partitioning in a Viverrid Assemblage (PhD Thesis). University of Natal, Pietermaritzburg, South Africa.

Madibo, T.M., 2017. Woody Species Increase and Development on the Southern end of Disaneng Village, Ratlou Muncipality, North West Province, South Africa (M.Sc. Thesis). North-West University, Mafikeng Campus, Mmabatho, South Africa.

McClure, M.F., Smith, N.S., Shaw, W.W., 1995. Diets of coyotes near the boundary of Saguaro National Monument and Tucson, Arizona. Southwest. Nat. 40, 101-125.

McKey, D., 1975. The ecology of coevolved seed dispersal systems. In: Gilbert, L.E., Raven, P.H. (Eds.), Coevolution of Animals and Plants. University of Texas Press, Austin, Texas, USA.

Meinzer, W.P., Ueckert, D.N., Flinders, J.T., 1975. Foodniche of coyotes in the Rolling Plains of Texas. J. Range Manage. 28, 22-27.

Milton, S.J., Dean, W.R.J., 2001. Seeds dispersed in dung of insectivores and herbivores in semi- 
arid southern Africa. J. Arid Environ. 47, 465-483.

Milton, S.J., Wilson, J.R.U., Richardson, D.M., Seymour, C.L., Dean, W.R.J., Iponga, D.M., Proches, S., 2007. Invasive alien plants infiltrate bird-mediated shrub nucleation processes in arid savanna. J. Ecol. 95, 648-661.

Minnie, L, Avenant. N.L., Kamler, J.F., Butler, H., Parker, D., Drouilly, M., du Plessis, J., Do Linh San, E., 2016. A conservation assessment of Canis mesomelas. In: Child, M.F., Roxburgh, L., Do Linh San, E., Raimondo, D., Davies-Mostert, H.T. (Eds.), The Red List of Mammals of South Africa, Swaziland and Lesotho. South African National Biodiversity Institute and Endangered Wildlife Trust, South Africa.

Mucina, L., Rutherford, M.C., 2006. The Vegetation of South Africa, Lesotho and Swaziland. Strelitzia 19. South African National Biodiversity Institute, Pretoria, South Africa.

Mujuru, L., 2011. Diospyros lycioides Desf. [Internet] Record from PROTA4U. Brink, M. and Achigan-Dako, E.G. (Editors). PROTA (Plant Resources of Tropical Africa), Wageningen, Netherlands. <http://www.prota4u.org/search.asp>.

Mukherjee, S., Goyal, S.P., Johnsingh, A.J.T., Leite Pitman, M.R.P., 2004. The importance of rodents in the diet of jungle cat (Felis chaus), caracal (Caracal caracal) and golden jackal (Canis aureus) in Sariska Tiger Reserve, Rajasthan, India. J. Zool. (Lond.) 262, 405-411.

Murdoch, J.D., Buyandelger, S., Cypher, B.L., 2009. Patterns of seed occurrence in corsac and red fox diets in Mongolia. J. Arid Environ. 73, 381-384.

Mureva, A., Ward, D., 2016. Spatial patterns of encroaching shrub species under different grazing regimes in a semi-arid savanna, eastern Karoo, South Africa. Afr. J. Range For. Sci. 33, 77-89. 
Murray, K.G., Russell, S., Picone, C.M., Winnett-Murray, K., Sherwood, W., Kuhlman, M.L., 1994. Fruit laxatives and seed passage rates in frugivores: effect on seedling establishment. Oecologia 93, 171-176.

Rebein, M., Davis, C.N., Abad, H., Stone, T., del Sol, J., Skinner, N., Moran, M.D., 2017. Seed dispersal of Diospyros virginiana in the past and the present: Evidence for a generalist evolutionary strategy. Ecol. Evol. 7, 4035-4043.

Reid, N., 1989. Dispersal of mistletoes by honeyeaters and flowerpeckers: components of seed dispersal quality. Ecology 70, 137-145.

Rosalino, L.M., Rosa, S., Santos-Reis, M., 2010. The role of carnivores as Mediterranean seed dispersers. Ann. Zool. Fennici 47, 195-205.

Rosalino, L.M., Santos-Reis, M., 2009. Fruit consumption by carnivores in Mediterranean Europe. Mammal Rev. 39, 67-78.

Schupp, E.W., Gómez, J.M., Jiménez, J.E., Fuentes, M., 1997. Dispersal of Juniperus occidentalis (western juniper) seeds by frugivorous mammals on Juniper Mountain, southeastern Oregon. Great Basin Nat. 57, 74-78.

Sebastián-González, E., 2017. Drivers of species' role in avian seed-dispersal mutualistic networks. J. Anim. Ecol. 86, 878-887.

Shackleton, R.T., Le Maitre, D.C., Richardson, D.M., 2015. Prosopis invasions in South Africa: population structures and impacts on native tree population stability. J. Arid Environ. $114,70-78$.

Skinner, J.D., Chimimba, C.T., 2005. The Mammals of the South African Subregion, Third Edition. Cambridge University Press, Cambridge, United Kingdom.

Slater, K., du Toit, J.T., 2002. Seed dispersal by chacma baboons and syntopic ungulates in 
southern African savannas. S. Afr. J. Wildl. Res. 32, 75-79.

Tew, E., Landman, M., Kerley, G.I.H., 2018. The contribution of the chacma baboon to seed dispersal in the eastern Karoo, South Africa. S. Afr. J. Wildl. Res. 48, 023002.

Traveset, A., Willson, M.F., 1997. Effect of birds and bears on seed germination of fleshy-fruited plants in temperate rainforests of southeast Alaska. Oikos 80, 89-95.

Van den Berg, E.C., 2010. Detection, Quantification and Monitoring Prosopis spp. in the Northern Cape Province of South Africa Using Remote Sensing and GIS (M.Sc. Thesis). North-West University, Potchefstroom, South Africa.

Varela, O., Bucher, E.H., 2006. Passage time, viability, and germination of seeds ingested by foxes. J. Arid Environ. 67, 566-578.

Verdú, M., García-Fayos, P., 1996. Nucleation process in a Mediterranean bird-dispersed plant. Funct. Ecol. 10, 275-280.

Walker, C., 1996. Signs of the Wild. Struik Publishers, Cape Town.

Willson, M.F., 1993. Mammals as seed-dispersal mutualists in North America. Oikos 67, 159176.

Wisz, M.S., et al., 2013. The role of biotic interactions in shaping distributions and realized assemblages of species: implications for species distribution modelling. Biol. Rev. 88, 15-30.

Zhou, Y., Newman, C., Xie, Z., Macdonald, D.W., 2013. Peduncles elicit large-mammal endozoochory in a dry-fruited plant. Ann. Bot. 112, 85-93. 


\section{Table 1}

Ecological parameters of the cape fox (Vulpes chama), bat-eared fox (Otocyon megalotis), and black-backed jackal (Canis mesomelas) studied on Benfontein Nature Reserve and Rooipoort Nature Reserve, South Africa, that were relevant for determining their potential to disperse seeds of fruit plants. $\mathrm{n}=$ sample size used to calculate mean

$$
\text { Mean adult Mean home-range Density }
$$

$\begin{array}{lll}\text { Species } & \text { body mass }(\mathrm{kg}) \quad \text { size }\left(\mathrm{km}^{2}\right)^{\mathrm{a}} \quad \text { (individuals } / \mathrm{km}^{2} \text { ) }\end{array}$

$\begin{array}{llll}\text { Benfontein } & & \\ \text { Cape fox } & 2.9(\mathrm{n}=11)^{\mathrm{b}} & 27.7(\mathrm{n}=5)^{\mathrm{b}} & 0.05^{\mathrm{b}} \\ \text { Bat-eared fox } & 3.7(\mathrm{n}=7)^{\mathrm{b}} & 5.0(\mathrm{n}=6)^{\mathrm{b}} & 1.07^{\mathrm{b}} \\ \text { Black-backed jackal } & 9.0(\mathrm{n}=11)^{\mathrm{b}} & 8.6(\mathrm{n}=14)^{\mathrm{c}} & 0.33^{\mathrm{b}}\end{array}$

Rooipoort $^{\mathrm{d}}$

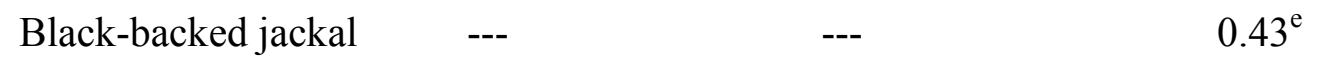

${ }^{\text {a }}$ Calculated using $95 \%$ minimum convex polygon method.

${ }^{\mathrm{b}}$ From Kamler et al., 2012.

${ }^{\mathrm{c}}$ From Kamler et al., 2019.

${ }^{\mathrm{d}}$ Cape foxes were not detected and bat-eared foxes had extremely low densities on Rooipoort, therefore these species were not studied on this site. The density of jackals was determined on Rooipoort, but this species was not captured and radio monitored.

${ }^{\mathrm{e}}$ From Klare et al., 2010. 


\section{Table 2}

Fruit consumption expressed as frequency of occurrence per scat (Occ), percentage of scat volume (Vol), percentage of ingested biomass (Bio), and $\mathrm{kg}$ of fruit consumed per $\mathrm{km}^{2}(\mathrm{Kg})$ of the cape fox (Vulpes chama), bat-eared fox (Otocyon megalotis), and blackbacked jackals (Canis mesomelas) on Benfontein and Rooipoort nature reserves, South Africa $(\mathrm{n}=$ number of scats analyzed).

\begin{tabular}{|c|c|c|c|c|c|c|c|c|c|c|c|c|c|c|c|c|}
\hline \multirow[b]{2}{*}{ Species - site } & \multicolumn{4}{|c|}{ Spring } & \multicolumn{4}{|c|}{ Summer } & \multicolumn{4}{|c|}{ Autumn } & \multicolumn{4}{|c|}{ Winter } \\
\hline & Occ & Vol & Bio & $\mathrm{Kg}$ & Occ & Vol & Bio & $\mathrm{Kg}$ & Occ & Vol & Bio & $\mathrm{Kg}$ & Occ & Vol & Bio & $\mathrm{Kg}$ \\
\hline \multicolumn{17}{|c|}{ Cape fox: Benfontein $(n=133)^{a}$} \\
\hline Diospyros lycioides & 4.5 & 1.3 & 0.3 & $<0.1$ & --- & --- & --- & --- & 10.8 & 2.8 & 2.0 & $<0.1$ & 18.4 & 14.0 & 31.3 & 0.3 \\
\hline \multicolumn{17}{|c|}{ Bat-eared fox: Benfontein $(n=177)^{b}$} \\
\hline Diospyros lycioides & 20.4 & 2.5 & 11.0 & 3.4 & 41.9 & 23.7 & 62.7 & 19.2 & 39.0 & 29.8 & 73.6 & 22.6 & 13.6 & 6.2 & 23.1 & 7.1 \\
\hline \multicolumn{17}{|l|}{ Jackal: Benfontein $(\mathrm{n}=312)^{\mathrm{c}}$} \\
\hline Diospyros lycioides & 11.2 & 4.0 & 1.5 & 0.3 & 5.4 & 2.2 & 0.8 & 0.2 & 15.8 & 14.4 & 6.8 & 1.5 & 9.7 & 5.1 & 2.3 & 0.5 \\
\hline Prosopis spp. & 0.0 & 0.0 & 0.0 & 0.0 & 27.0 & 22.7 & 12.3 & 2.8 & 3.5 & 1.9 & 0.6 & 0.1 & 1.1 & 0.0 & 0.0 & 0.0 \\
\hline Other (unidentified) & 4.5 & 0.0 & 0.0 & 0.0 & 1.4 & 0.0 & 0.0 & 0.0 & 5.3 & 0.0 & 0.0 & 0.0 & 5.4 & 0.0 & 0.0 & 0.0 \\
\hline \multicolumn{17}{|l|}{ Jackal: Rooipoort $(\mathrm{n}=522)^{\mathrm{c}}$} \\
\hline Diospyros lycioides & 19.0 & 4.5 & 3.0 & 0.9 & 4.2 & 2.9 & 1.4 & 0.4 & 39.8 & 24.6 & 19.4 & 5.8 & 8.3 & 3.1 & 1.6 & 0.5 \\
\hline Ziziphus mucronata & 32.0 & 8.4 & 5.6 & 1.7 & 9.3 & 5.0 & 3.9 & 1.2 & 71.5 & 52.9 & 47.2 & 14.1 & 81.8 & 60.4 & 51.3 & 15.3 \\
\hline Grewia flava & 20.0 & 4.2 & 2.7 & 0.8 & 45.8 & 37.0 & 24.9 & 7.4 & 5.7 & 3.3 & 1.8 & 0.5 & 2.8 & 0.1 & 0.2 & 0.1 \\
\hline Other (unidentified) & 10.0 & 0.1 & 0.0 & 0.0 & 2.5 & 0.1 & 0.1 & $<0.1$ & 15.4 & 0.1 & 0.1 & $<0.1$ & 7.2 & 0.1 & 0.1 & $<0.1$ \\
\hline
\end{tabular}

${ }^{a}$ See Klare et al., (2014) for methodological details of the scat analysis for cape foxes. Too few cape fox scats $(\mathrm{n}<15)$ were collected in summer, therefore this season was omitted from analyses.

${ }^{\mathrm{b}}$ See Klare et al., (2011) for methodological details of the scat analysis for bat-eared foxes. 
${ }^{\mathrm{c}}$ See Klare et al., (2010) for methodological details of the scat analysis of black-backed jackals. 
Fig. 1. Frequency of occurrence of seeds from fruit plants in the scats of cape foxes (Vulpes chama), bat-eared foxes (Otocyon megalotis), and black-backed jackals (Canis mesomelas) on Benfontein Nature Reserve, South Africa. For cape foxes and bat-eared foxes, only seeds of Diospyros lycioides were consumed, whereas jackals consumed both D. lycioides (solid grey bar) and alien invasive Prosopis spp. (hashed grey bar). The “*” indicates data were not included for cape foxes in summer because of a low sample size.

Fi. 2. Frequency of occurrence of seeds from different fruit plants in the scats of black-back jackals (Canis mesomelas) on Rooipoort Nature Reserve, South Africa. 


\section{Highlights}

- Foxes and jackals consumed large amounts of wild fruit in South Africa

- Jackals had a higher seed dispersal potential than foxes

- Seed dispersal potential of South African canids is greater than previously known

- Canids likely assist the regeneration of fruit plants in semi-arid habitat 
Click here to download high resolution image




Click here to download high resolution image

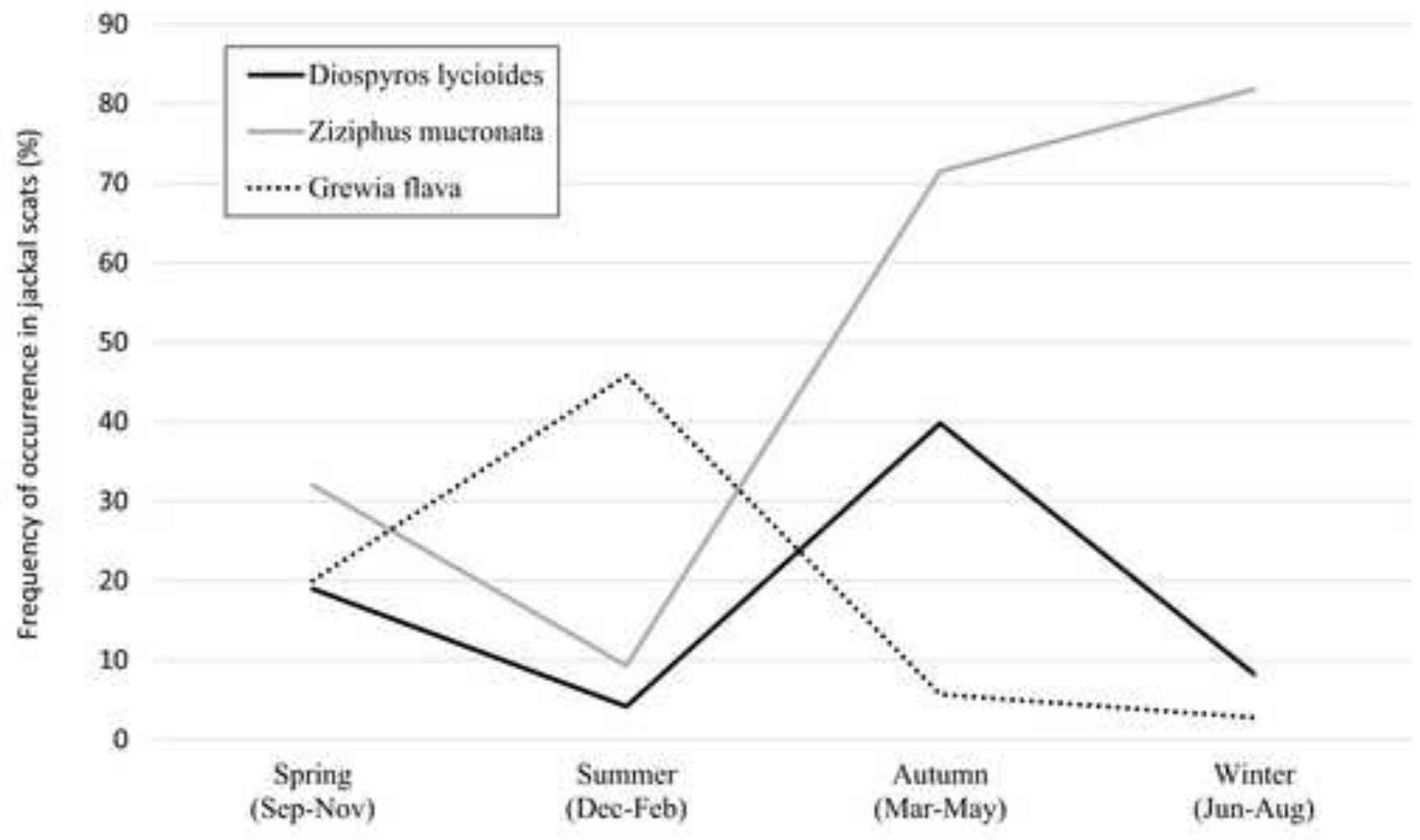

